\title{
GRAVITY ANOMALIES AROUND JAPAN
}

\author{
Yasuhiro Ganeko* and Yukio Harada
}

Received 1981: August 3

\begin{abstract}
A free-air gravity anomaly map in the vicinity of the continental shelf around Japan was compiled based on dense gravity surveys made by the Hydrographic Department of Japan (JHD). The map is presented as a supplement of the present paper. Some 92,800 gravity data contributed to the compilation of the map.

A $10^{\prime} \times 10^{\prime}$ block mean gravity anomaly data file was produced based on the JHDGF-T81 gravity data file which includes some 540,000 gravity sites in the western and southern Pacific areas. $10^{\prime} \times 10^{\prime}$ block mean anomalies were computed in a rectangular area bordered by the parallels $\mathrm{N} 20^{\circ}$ and $\mathrm{N} 50^{\circ}$, and the meridians $\mathrm{E} 120^{\circ}$ and $\mathrm{E} 150^{\circ}$. The least-squares estimation technique was adopted in computation. The block mean gravity anomalies are shown symbolically in figures. The data file of mean gravity anomalies can be used for the computation of a detailed gravimetric geoid and for other geophysical uses.
\end{abstract}

\section{Introduction}

The Hydrograhic Department of Japan (JHD) has been carrying out gravity measurements at sea since 1964 by use of two sets of vibrating string-type sea gravity meters, which are called T.S.S.G. (Tokyo Surface Ship Gravity Meter) developed by the Ocean Research Institute, University of Tokyo (Tomoda and Kanamori, 1962; Segawa, 1970a, b; Fujimoto, 1976). The fully organized gravity surveys by JHD have been carried out for the publication of the Basic Map of the Sea over the continental shelf around Japan since 1967. The series of the Basic Map of the Sea are composed of four $1 / 200,000$ scale maps corresponding to four items, the bathymetric topography, the sub-bottom structure, the total magnetic force and the free-air gravity anomaly. Two survey ships owned by JHD have been engaged in this large project, which are Shoyo (1852 gross tons) and Meiyo (361 gross tons). The information of gravity surveys can be referred to the Data Report of Hydrographic Observations, Series of Astronomy and Geodesy published every year. The number of published gravity anomaly maps of the Basic Map. of the Sea amounts to 47 sheets at the time March 1981.

Some of individual data were published in the data report mentioned above. Because of the recent large amount of data, publication of individual data in the printed form has become impossible, so all the gravity data have been compiled in a machine readable magnetic tape form. The status of the gravity data file of JHD and the recording format of the file are found in Ganeko and Koyama (1981). Some 92,800 gravity data observed by JHD have been compiled in the data file at present. The gravity survey cruises are listed in Table 1 which includes the name of cruise,

* Astronomical Division 
Table 1 Gravity survey cruises of JHD and the number of observation sites

\begin{tabular}{|c|c|c|c|}
\hline Name of Cruise & Year & Cruise Ident. & Number of Sites \\
\hline Vicinity of Yamato-Tai & 1965 & $65 \mathrm{YT}$ & 347 \\
\hline Offing of Tokati and Tohoku & 1968 & $68 \mathrm{TK}$ & 1370 \\
\hline Offing of Akita & 1968 & $68 \mathrm{AK}$ & 884 \\
\hline offing of Niigata & 1968 & $68 \mathrm{NI}$ & 2014 \\
\hline Offing of Isikari and Rumoi & 1970 & 7OIR & 3287 \\
\hline South Offing of Sanriku & 1970 & 70SN & 1389 \\
\hline Offing of Soya and Abasiri & 1971 & $71 \mathrm{SA}$ & 1727 \\
\hline Offing of Monbetu & 1972 & $72 \mathrm{MO}$ & 447 \\
\hline Offing of Hukui & 1972 & $72 \mathrm{HU}$ & 1877 \\
\hline Offing of Kusiro & 1972 & $72 \mathrm{KU}$ & 2405 \\
\hline Offing of Hiyama & 1972 & $72 \mathrm{HI}$ & 1519 \\
\hline Offing of Hidaka and Iburi & 1972 & $72 \mathrm{HD}$ & 2635 \\
\hline Offing of Hukuoka & 1973 & $73 \mathrm{HK}$ & 1664 \\
\hline Offing of Kagosima & 1973 & $73 \mathrm{KG}$ & 4158 \\
\hline Offing of Miyazaki & 1973 & $73 \mathrm{MI}$ & 4109 \\
\hline Offing of Koti & 1973 & $73 \mathrm{KO}$ & 2452 \\
\hline Offing of Nagasaki & 1974 & $74 \mathrm{NG}$ & 5525 \\
\hline Offing of Tottori & 1974 & $74 \mathrm{TR}$ & 1430 \\
\hline Offing of Kagosima & 1974 & $74 \mathrm{KG}$ & 3450 \\
\hline Offing of Okinawa & 1975 & $750 \mathrm{~K}$ & 3595 \\
\hline offing of Yamaguti & 1975 & $75 \mathrm{YM}$ & 2762 \\
\hline Offing of Simane & 1975 & $75 \mathrm{SI}$ & 2957 \\
\hline Offing of Boso & 1975 & $75 \mathrm{BO}$ & 6154 \\
\hline Vicinity of South Io-Sima & 1976 & $76 \mathrm{IK}$ & 1463 \\
\hline Offing of Okinawa & 1976 & $760 \mathrm{~K}$ & 4831 \\
\hline Vicinity of Miyako-Sima & 1976 & $76 M Y$ & 3287 \\
\hline Offing of Kasima-Nada & 1976 & $76 \mathrm{IK}$ & 3215 \\
\hline South Offing of Joban & 1977 & 77JO & 6017 \\
\hline North Offing of Joban & 1978 & $78 \mathrm{JO}$ & 6701 \\
\hline Offing of Kisyu and Tokai & 1980 & $80 \mathrm{KT}$ & 4226 \\
\hline Offing of Isikawa & 1980 & 80IS-A & 3532 \\
\hline Offing of Simane & 1980 & $80 I S-B$ & 1377 \\
\hline Total & & & 92807 \\
\hline
\end{tabular}




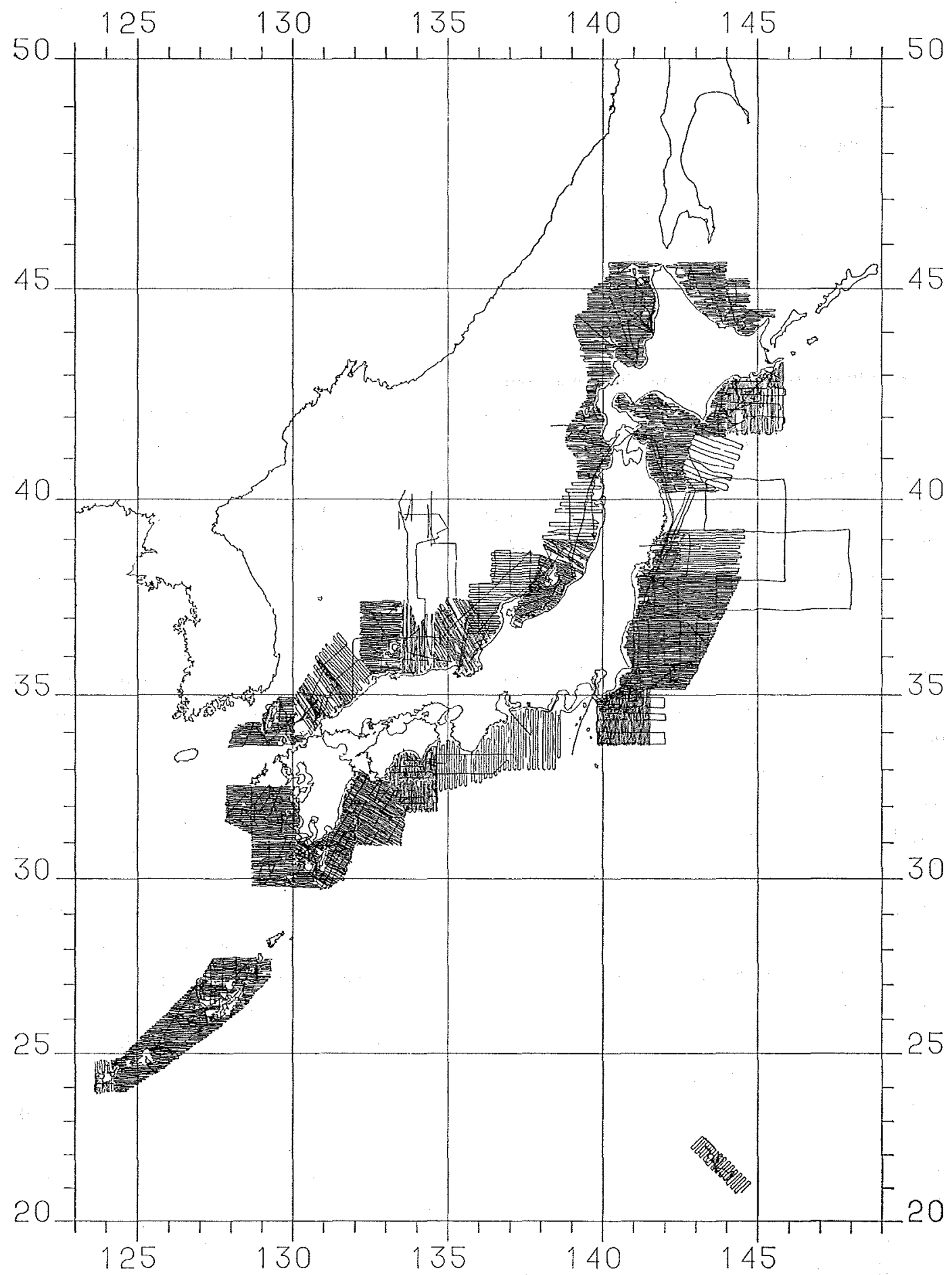

Figure 1 Gravity survey track chart of the cruises made by JHD during 1964-1980 
observation year, cruise identification and number of gravity observation sites for each cruise. Figure 1 is the track chart of above cruises showing the survey areas and the observation density. Some vacant areas are unsurveyed or under data processing areas. The spacing of the survey tracks was taken as two nautical miles as a rule, but four or five nautical miles spacing was sometimes adopted to save ship time. The gravity observation by the sea gravity meter is made every five or ten minutes, which is necessary to filter out the disturbing vertical acceleration. The obtained gravity value, therefore, is the mean value during the observation interval. Since the surveying speed of the ship is usually 9 to 11 knots, the gravity observation sites are spaced out 1.4 to $3.4 \mathrm{~km}$ apart along the survey track. A brief explanation of the sea gravity meter and the observation method can be seen in Ganeko et al. (1978).

\section{Compilation of gravity anomaly map}

The raw gravity data measured on board the survey ship are calibrated by the gravity values of the base ports. The differences between the outputs of the gravity meter and the base gravities after the initial calibration are considered to be some drifts of the gravity meter and the drifts are corrected under the linear assumption between port calibrations. Then the fundamental gravity data file is created. The track chart and the water depth data taken along the gravity survey are stored in digital forms after the cruise, so the position and the depth data files are created. Above three data files are the basic data for the successive data processing.

The Eötvös corrections and the normal gravities are calculated from the position data file and the Bouguer corrections are obtained from the depth data file. The finaly produced gravity data file comprises observation time, position, depth, gravity, free-air anomaly, Bouguer anomaly and other cruise information. The procedure of the data processing at JHD should be referred to Ganeko et al. (1978). After the creation of the final data file, numerical figures of gravity anomalies are plotted on a 1/200,000 reduced scale map by use of a machine, and the contour maps of free-air and Bouguer anomaly are produced by hand with $10 \mathrm{mGals}$ contour interval. In this procedure the reliability of the gravity survey is examined by the gravity differences at intersecting points of survey tracks, and unreasonable data, if found, are deleted from the data file. The produced contour map of free-air gravity anomaly is adopted as the basis of the publication of the Basic Map of the Sea.

One of the purposes of the present paper is to arrange a free-air gravity anomaly map showing the feature of the anomaly field around Japan at a glance by rearranging the $1 / 200,000$ scale gravity anomaly maps prepared for the publication of the Basic Map of the Sea. The $1 / 200,000$ scale maps are converted photographically to $1 / 1,000,000$ scale maps. Five sheets of $1 / 1,000,000$ scale gravity anomaly maps for different areas are arranged by combining the maps photographically reduced. In this procedure $20 \mathrm{mGal}$ contour interval is adopted. The five anomaly maps are conbined together again, and finally a sheet of gravity anomaly map on 1/3,000,000 scale is produced. A copy of the map is presented as a supplement of the present paper. In the map, positive and negative anomalies are expressed by red and blue contour lines, respectively. The wide red lines correspond to zero anomaly. This map is the first one showing the detailed feature of the gravity anomaly field in the vicinity of the continental shelf almost all around Japan, and may be good for the geodetic and geophysical use. For convenience' sake the five anomaly maps which are the basis of the compilation of the 1/3,000,000 scale map are shown in Figures 2a, 2b, 2c, 2d and 2e. 


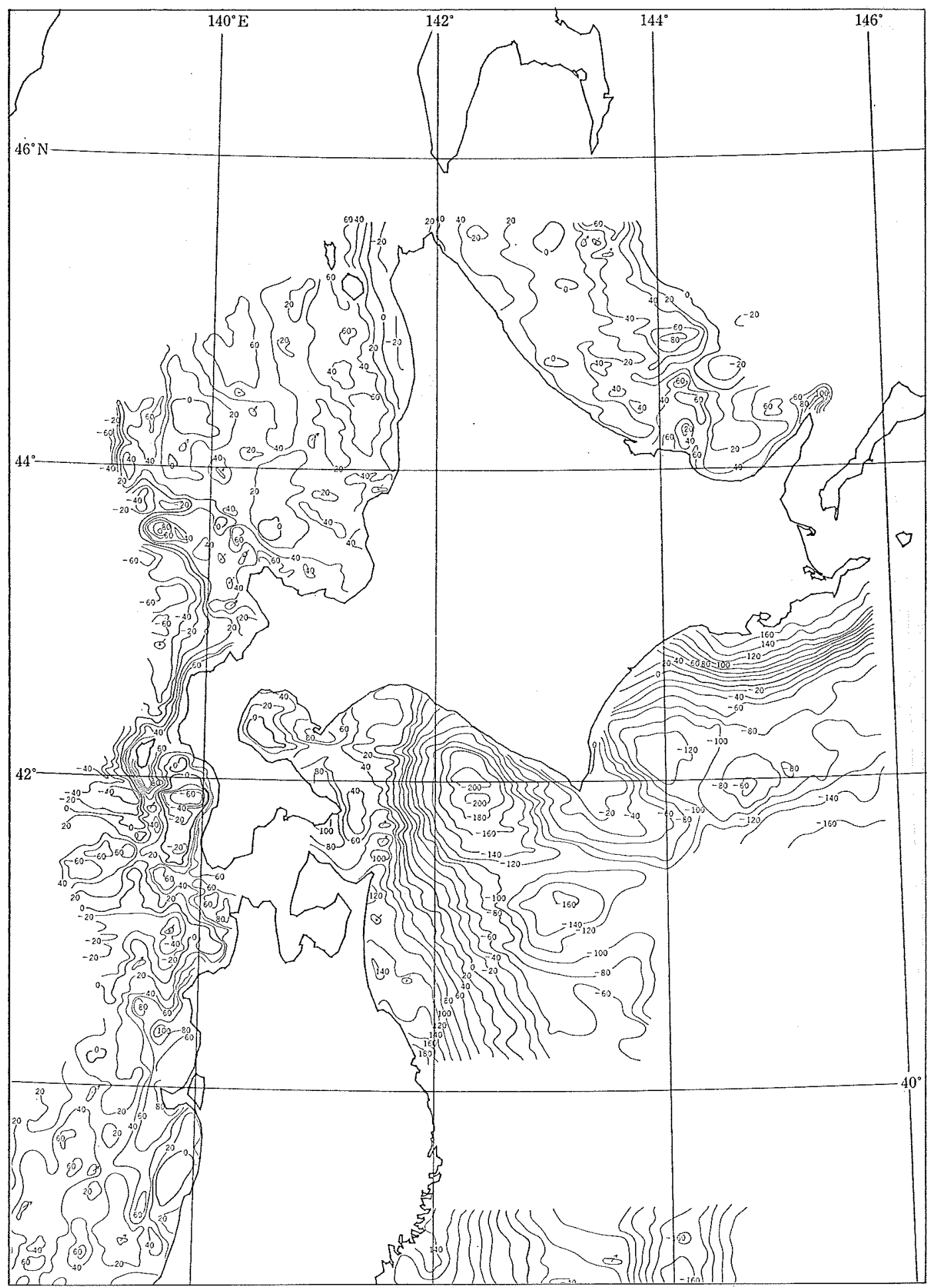

Figure 2a Free-air gravity anomalies around Hokkaido. Contour interval is $20 \mathrm{mGal}$ 


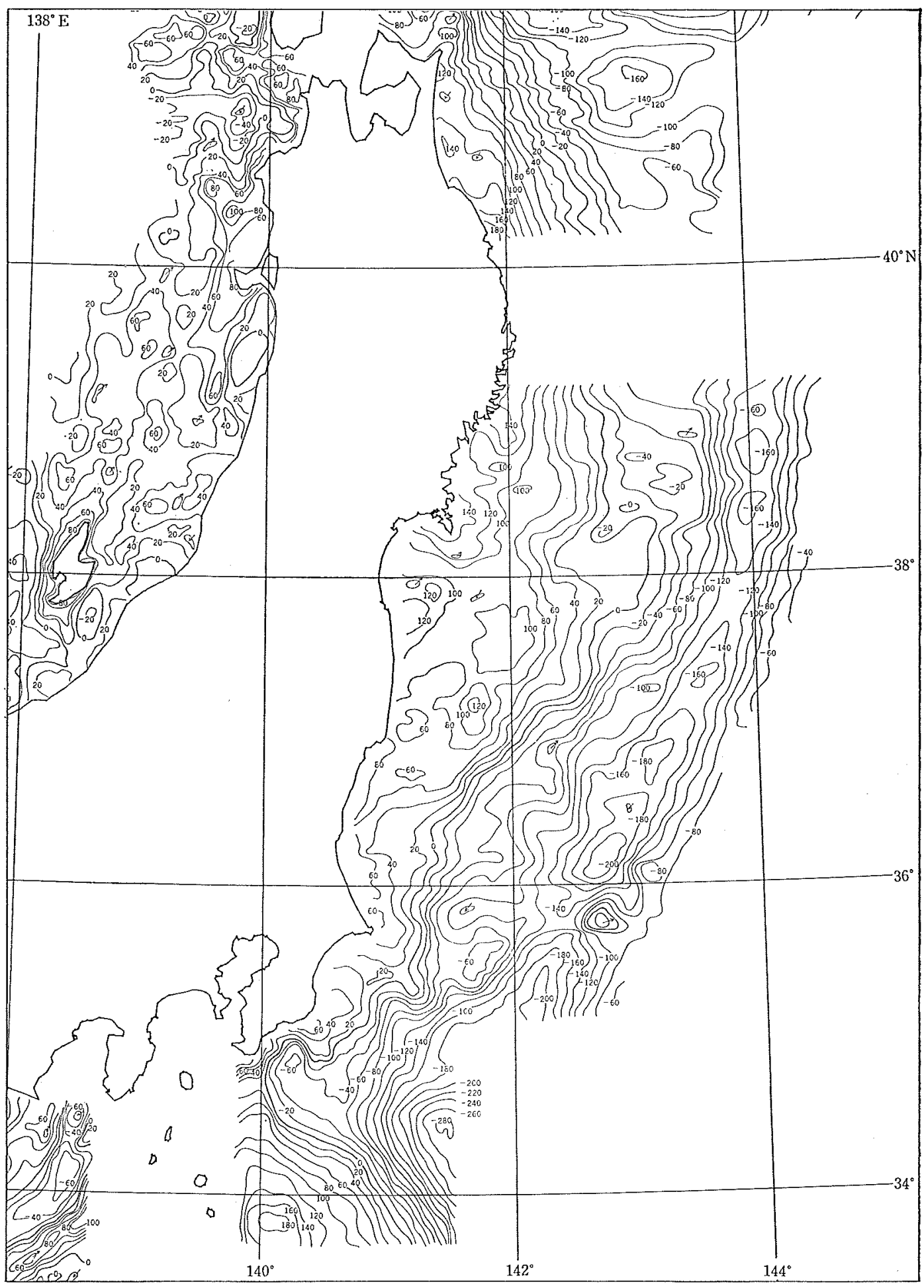

Figure 2b Free-air gravity anomalies around northern half of Honsyu. Contour interval is $20 \mathrm{mGal}$ 


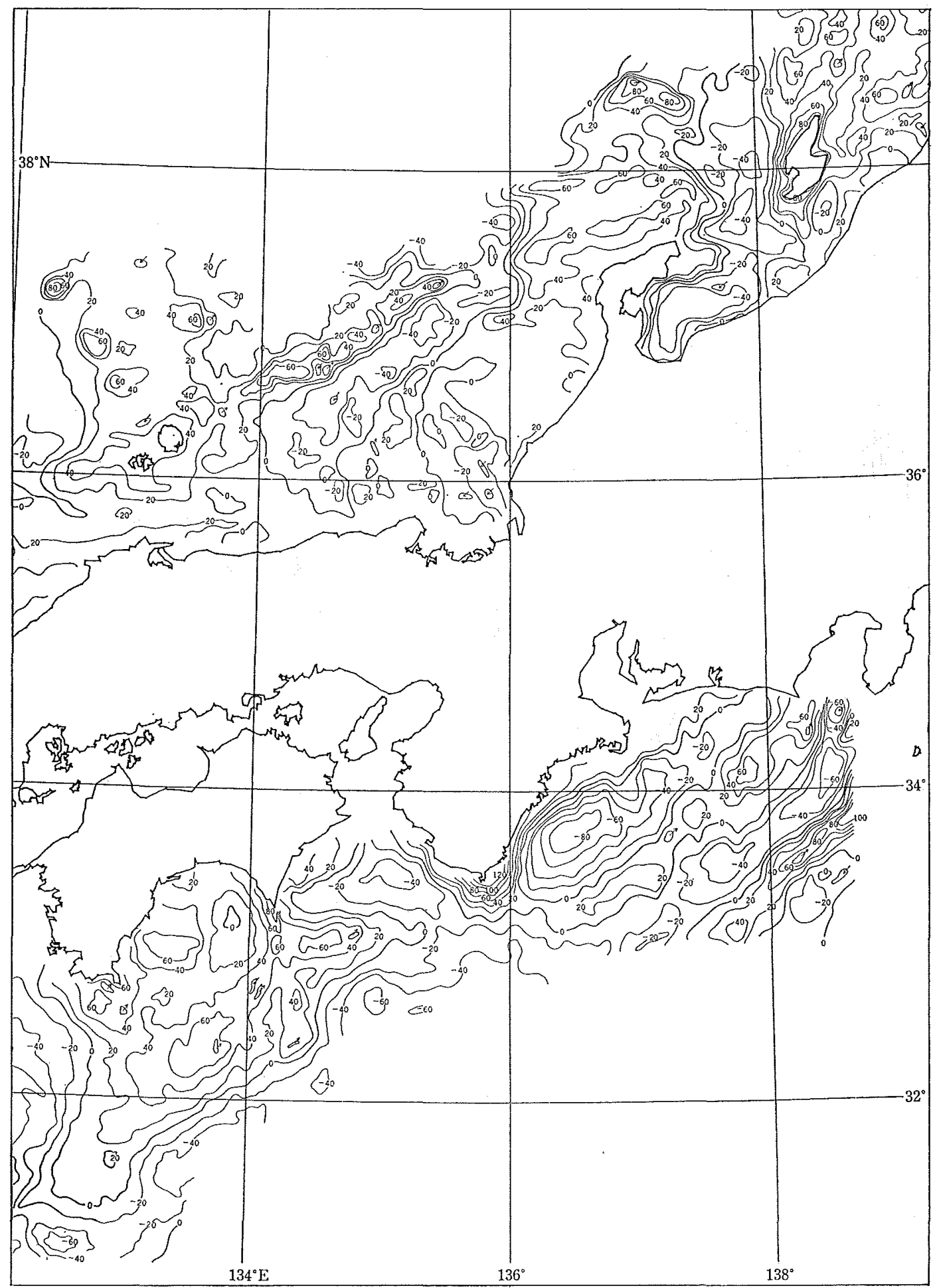

Figure 2c Free-air gravity anomalies around western half of Honsyu. Contour interval is $20 \mathrm{mGal}$ 


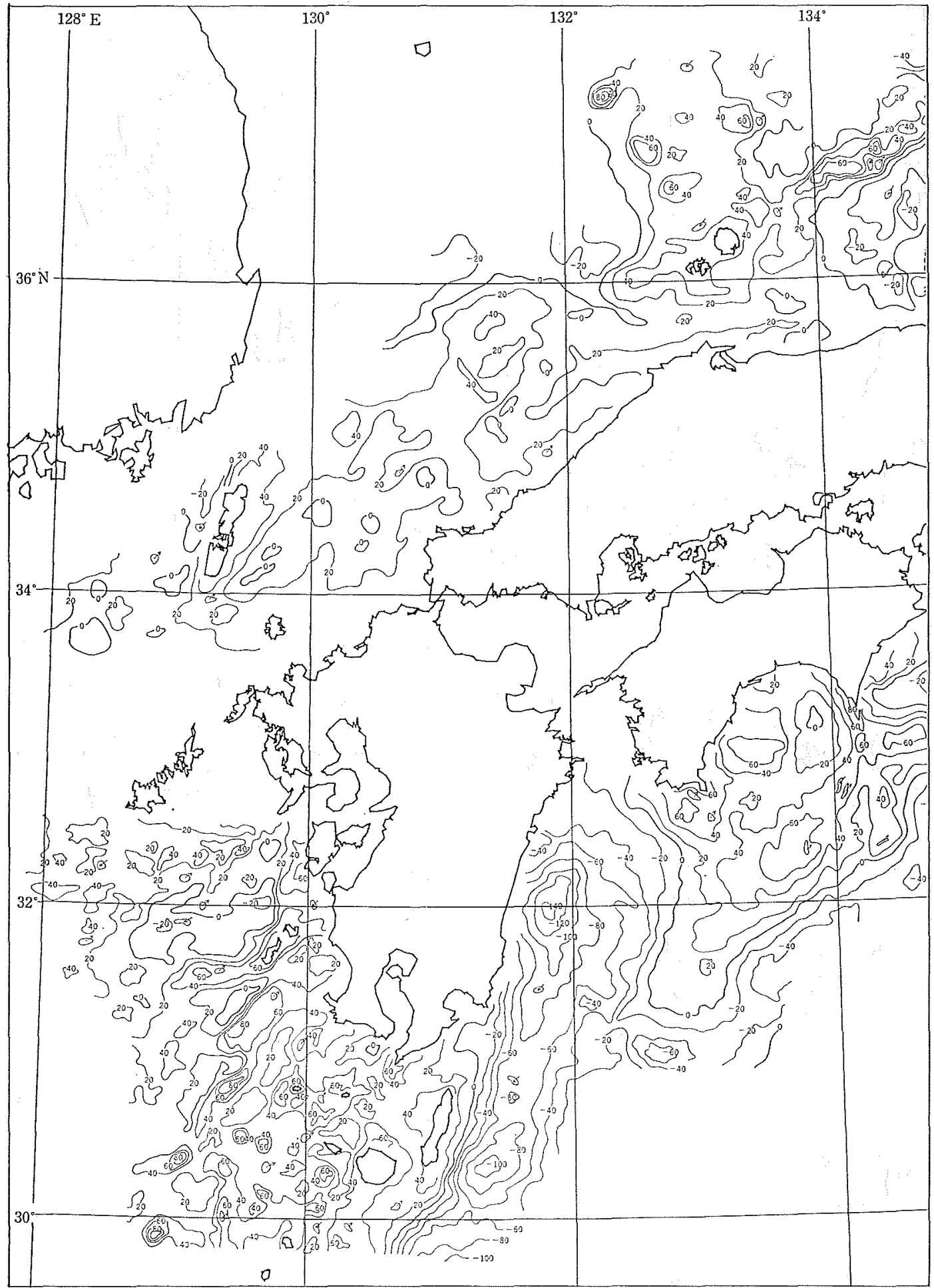

Figure 2d Free-air gravity anomalies around Sikoku and Kyusyu. Contour interval is $20 \mathrm{mGal}$ 


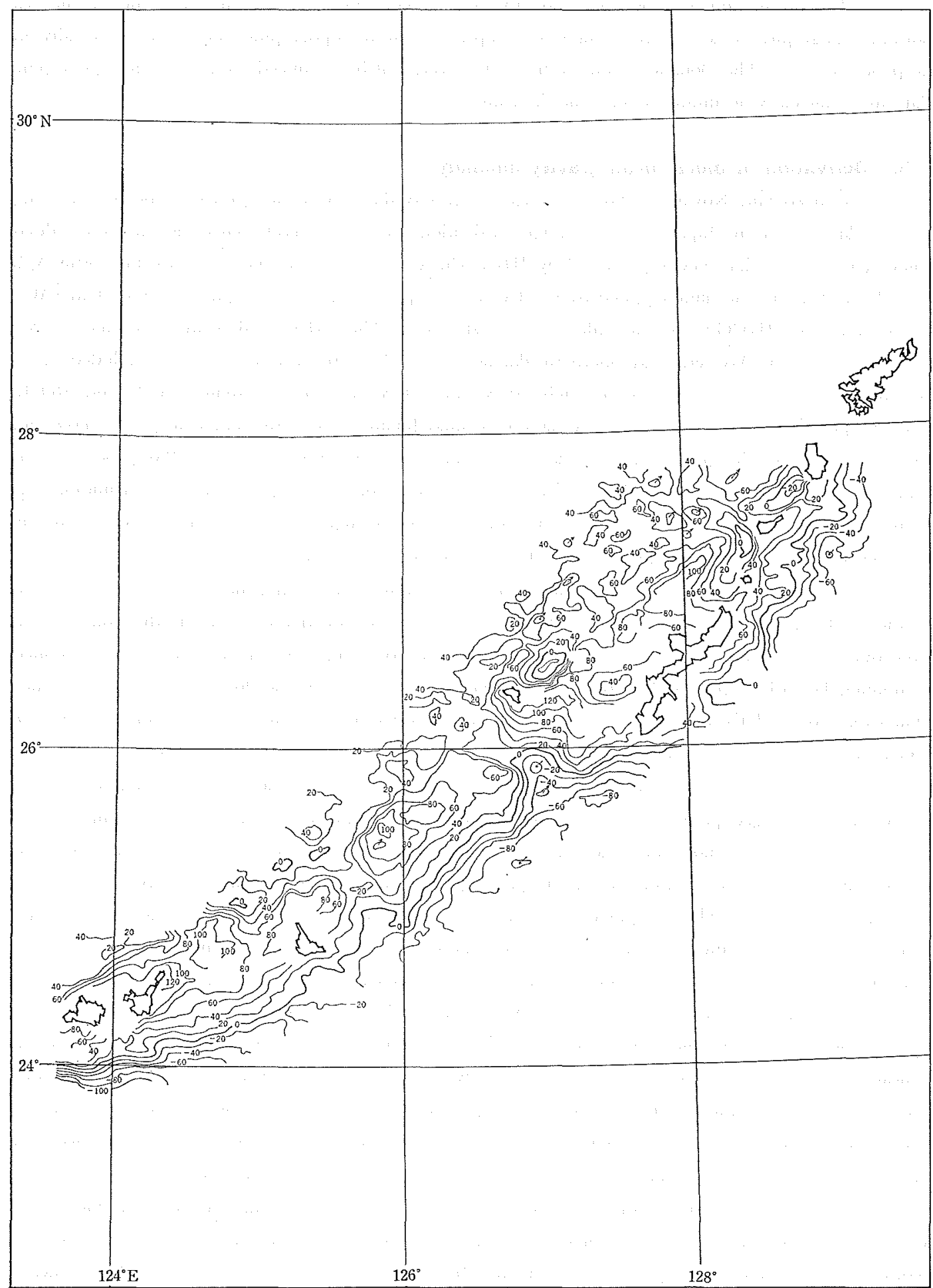

Figure 2e Free-air gravity anomalies around Nansei Syoto. Contour interval is $20 \mathrm{mGal}$ 
The production of a Bouguer anomaly map is not done because the data file of the sea bottom topography is not ready enough to compute accurate topographic corrections especially in deep ocean areas. The Bouguer anomaly map, however, will be produced soon after the topographic data are sufficiently accumulated into the data file.

\section{Derivation of block mean gravity anomaly}

Ganeko and Koyama (1981) arranged a gravity data file named JHDGF-T80 by collecting gravity data taken by Japanese and foreign institutions as well as JHD. Since then we have added some 9,000 gravity data newly processed by $\mathrm{JHD}$, which are cruises labeled as $80 \mathrm{KT}$ and $80 \mathrm{IS}-\mathrm{A}, \mathrm{B}$ (see Table 1), and the data supplied by the Defence Mapping Agency Aerospace Center (DMAAG) to the data file. JHDGF-T81 data file is newly produced. The JHDGF-T81 comprises some 540,000 gravity sites in the Western and Southern Pacific area. 262,200 gravity sites are included in a rectangular area bordered by the parallels $20^{\circ} \mathrm{N}$ and $50^{\circ} \mathrm{N}$ and the meridians $120^{\circ} \mathrm{E}$ and $160^{\circ} \mathrm{E}$. The computation of accurate geoid undulations around Japan is one of the major targets of JHD, and the arrangement of the gravity data file has been done along the target. Ganeko (1980) pointed out that $10^{\prime} \times 10^{\prime}$ block mean anomalies at least are necessary for the computation of geoid undulations with a relative accuracy of $10 \mathrm{~cm}$. We, therefore, try to arrange a $10^{\prime} \times 10^{\prime}$ block mean anomaly data file as a basis of the computation of the gravimetric geoid around Japan.

To derive block mean gravity anomalies from point gravity data, the least-squares estimation method (Heiskanen and Moritz, 1967; Moritz, 1972) can be effectively used. In the computation procedure an anomaly covariance function is necessary. We adopt the anomaly covariance obtained combining GEM8 geopotential model (Wagner et al., 1976) with the local anomaly covariance (Ganeko, 1980). This anomaly covariance was used already to make test computations of $10^{\prime} \times 10^{\prime}$ block mean anomalies in Ganeko and Koyama (1981).

Adopting the same method as theirs, we compute $10^{\prime} \times 10^{\prime}$ block mean anomalies by use of the newly arranged point gravity data file JHDGF-T81. Point gravity data distributed in and $2.5^{\prime}$ around each $10^{\prime} \times 10^{\prime}$ block are adopted in the least-squares estimation procedure, and $7.5 \mathrm{mGals}$ random error is assumed uniformly for the point gravity data. Any systematic gravity measurement error is not assumed. The computed block means may sustain effect of systematic gravity data errors of several to a few tens mGals as well as random errors especially in the data sparse areas. The least-squares estimation method estimate errors of block means scattering in the range 2 to 20 mGals depending on the gravity sites distribution on the basis of only the assumed random gravity errors. Block means occasionally cannot be estimated under the formerly adopted data distribution condition in the data sparse areas. In such cases we try to estimate block means by use the block mean anomalies computed already and can adopt the least-squares estimaiton technique again for this second step. The covariance function of $10^{\prime} \times 10^{\prime}$ block mean anomalies is necessary this time and it can be derived from the point anomaly covariance function used in the first step (e.g. see Ganeko and Koyama, 1981). Although the block covariance depends on the absolute block size we adopt for convenience' sake the block covariance function based on the block size of $10^{\prime} \times 10^{\prime}$ block at $30^{\circ}$ latitude for the use around Japan. It is possible because the estimated block means by the least-squares estimation method weakly depend on a slight change of the covariance function. In the actual computation procedure, three block covariance functions are numerically prepared in 


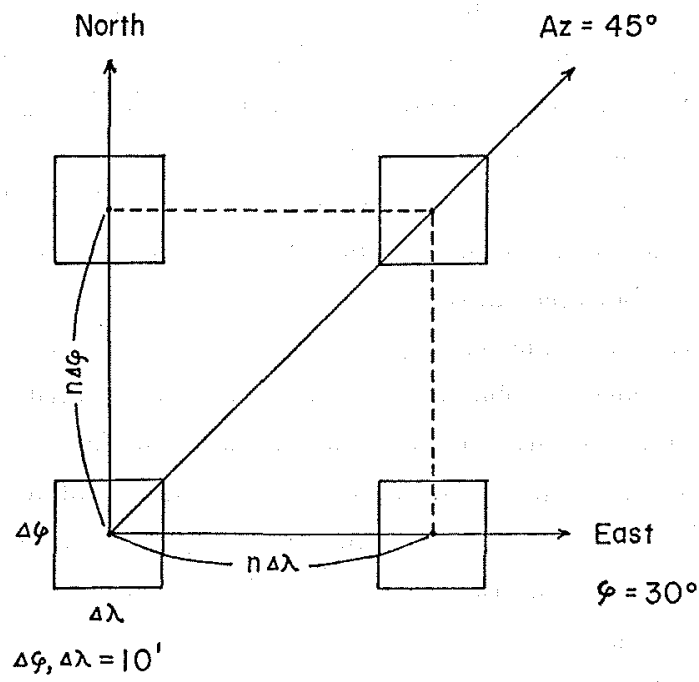

Figure 3a Three directions in which block anomaly covariance functions are computed

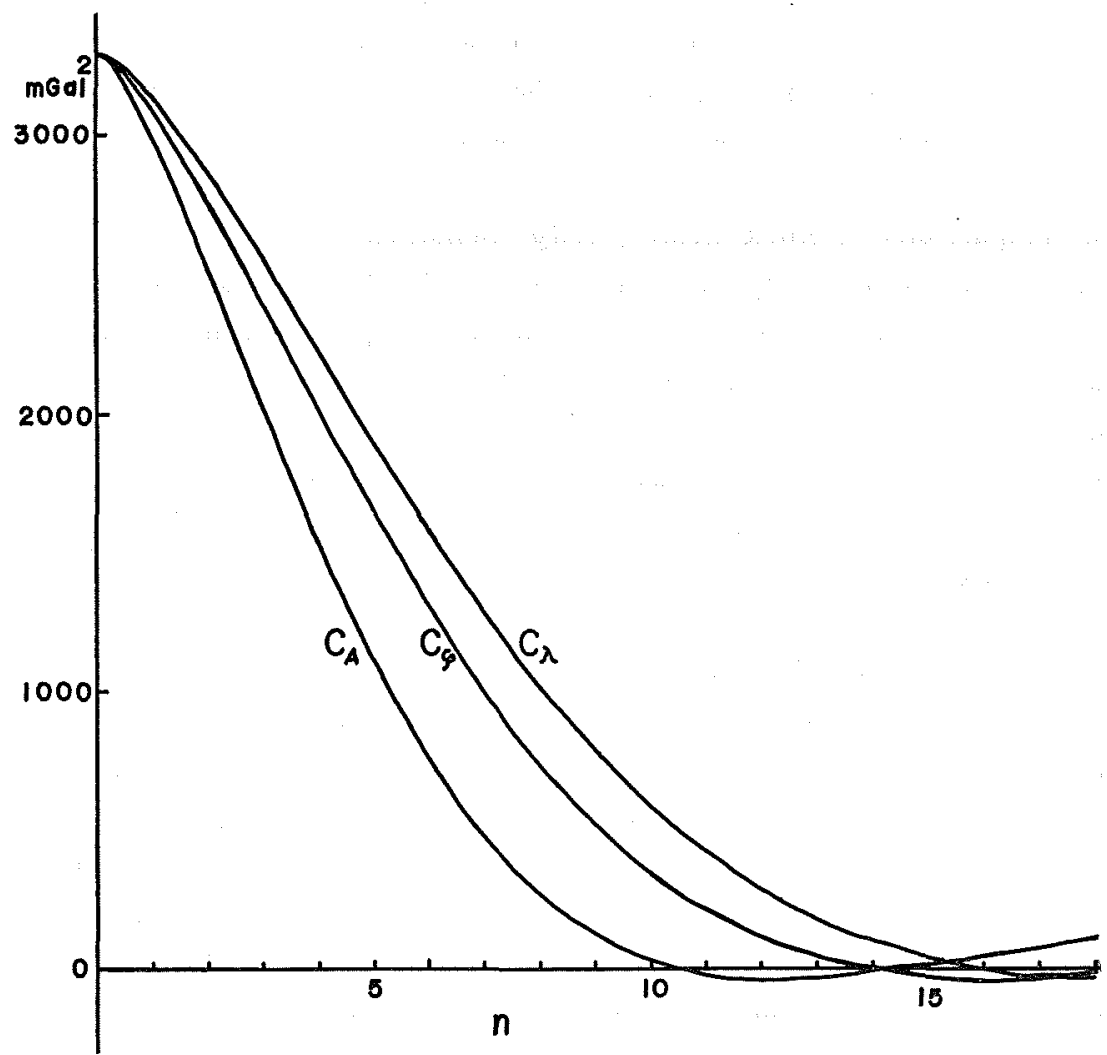

Figure $3 \mathrm{~b}$ Block anomaly covariance functions in three directions: $C_{5}$-North, $C_{\lambda}$-East (West), $C_{A}$-Azimuth $45^{\circ} . \mathrm{n}$ is the distance between two blocks in the unit of the block size. 
advance which are corresponding to three directions of block spacing as shown in Figure 3a. The covariance values are stored in the memory of the electronic computer. Figure $3 \mathrm{~b}$ shows corresponding three block covariance functions labeled $C_{\varphi}$ (North direction), $C_{\lambda}$ (East direction) and $C_{A}$ (azimuth $45^{\circ}$ direction). The positional relation of two blocks is actually approximated to one of the three cases, and the covariance value of the two blocks is obtained by the interpolation based on the distance between the blocks by use of the tabulated covariance values. Above procedure includes naturally an assumption of isotropic statistical characteristics of the gravity anomaly field.

After the application of the least-squares estimation technique twice to the gravity data file JHDGF-T81 as explained above, we obtain a $10^{\prime} \times 10^{\prime}$ block mean gravity anomaly file identified as JHDGF-T81-BL10. JHDGF-T81-BL10 is symbolically shown in Figure 4 to indicate the feature of the gravity anomaly field near Japan. Symbols are assigned as follows: (C) for $|\overline{\Delta g}| \geqq 200 \mathrm{mGal}$; $\bullet$ for $100 \leqq|\overline{\Delta g}|<200 ; \triangle$ for $50 \leqq|\overline{\Delta g}|<100 ; \odot$ for $25 \leqq|\overline{\Delta g}|<50 ;+$ for $10 \leqq|\overline{\Delta g}|<25 ; \times$ for $|\overline{\Delta g}|<10$. Positive and negative anomalies are distinguished by red and black, respectively. On the symbolical back ground, gravity anomalies are colored according to three anomaly ranges; $25 \mathrm{mGal} \leqq|\overline{\Delta g}|<100$ mGal, $100 \leqq|\overline{\Delta g}|<200$ and $|\overline{\Delta g}| \geqq 200$, by using warm colors for positive anomalies and cool colors for negative anomalies.

The largest positive anomalies occur near the Ogasawara Islands and the largest negative anomalies occur along the axses of the Izu-Ogasawara Trench and the Kuril-Kamchatka Trench. We see apparently that large negative anomalies are accompanied with large positive anomalies and the low level positive anomalies occuring seaward of the trenches are also apparent. These gravity highs are interpreted geophysically as a motive of the subduction of the ocean lithosphere (Fujimoto, 1976; Tomoda et al., 1980; Tomoda and Fujimoto, 1980).

\section{Some comparisons of block mean gravity anomalies}

$1^{\circ} \times{ }^{\circ}$ block mean gravity anomalies are calculated from the $10^{\prime} \times 10^{\prime}$ block means (JHDGF-T81-BL10) obtained in the previous section by a simple averaging of the $10^{\prime} \times 10^{\prime}$ block means included in each $1^{\circ} \times 1^{\circ}$ block. The calculated $1^{\circ} \times 1^{\circ}$ block mean gravity anomalies are identified by JHDGF-T81-BL60.

There are some files of $1^{\circ} \times 1^{\circ}$ block anomalies covering the area near Japan. We compare JHDGF-T81-BL60 with (a) DMAAC's data (1981)*, (b) LAMONT's data (Watts and Leeds, 1977) and (c) JHDGF-1 (Ganeko, 1980). The results of the comparisons are shown in Table 2 and Figures $5 \mathrm{a}, 5 \mathrm{~b}$ and $5 \mathrm{c}$. In the comparison with DMAAC's data there occured one abnormally large difference of $150 \mathrm{mGals}$ and the difference is deleted from Table 2. In three cases the number of comparisons with difference less than $5 \mathrm{mGals}$ is always around $50 \%$ of the total comparisons. The JHDGF-1 agrees best with JHDGF-T81-BL60, which is reasonable because the JHDGF-1 is mainly based on the free-air gravity anomaly maps published around Japan and the maps were produced on the basis of the common gravity data compiled into JHDGF-T81. The mean differences $-0.2,-1.0$ and $-0.3 \mathrm{mGals}$ are all small and the sources of these differences cannot be made clear taking the density of the gravity observation sites and the accuracy of sea gravity measurements into consideration. Such small differences however cannot be neglected in the computation of the

* Defence Mapping Agency Aerospace Center $1^{\circ} \times 1^{\circ}$ mean gravity anomaly field, January 1981 . 
gravimetric geold. The gravinetric geoldal height is obtalred through the integration of gravity anomaly data in a vast area, and consequently the effect of a small systematic difference is not negligible. For example, the efrect amounts to almost 2 meters when the mean difference of $0.3 \mathrm{mGals}$ is taken as a systematic gravity data error over the cap area with $15^{\circ}$ angular radius. The detection of such sinall systematic error is quite difricult under the present sea gravinetry. We may, therefore, be able to point out that the absolute gravinetric geoldal height cannot be deternined nore accurately than 1 meter for

Table 2 Comparison of JHDGF-T81-BL60 $1^{\circ} \times 1^{\circ}$ block mean anomalits with DMAAC, LAMONT and JHDGF-1 block means

\begin{tabular}{|c|c|c|c|}
\hline & DMAAC* & LAMONT & JHDGF-1 \\
\hline Number of Blocks Compared & 463 & 592 & 353 \\
\hline Mean Difference & $-0.2^{\text {malela }}$ & $-1.0^{\text {wonis }}$ & $-0.3^{\ln 0 \mathrm{al}}$ \\
\hline RMS Difference & 12.0 & 13.6 & $10 .+$ \\
\hline Maximum Positive Difference & 61 & 87 & 29 \\
\hline Maximum Negative Difference & -66 & -58 & -44 \\
\hline $\begin{array}{l}\text { Number of Blocks } \\
\text { IDif. I } \leqq 5 \text { mCals }\end{array}$ & $\begin{array}{c}225 \\
(49 \%)\end{array}$ & $\begin{array}{c}308 \\
(52 \%)\end{array}$ & $\begin{array}{c}183 \\
(52 \%)\end{array}$ \\
\hline $\begin{array}{l}\text { Number of Blocks } \\
\text { |Diff. } \mid>35 \text { mGals }\end{array}$ & $\begin{array}{c}9 \\
(2 \%)\end{array}$ & $\left(4 \frac{22}{0,0}\right)$ & $(2 \stackrel{4}{4})$ \\
\hline
\end{tabular}

* after one abnormaly large difference of $150 \mathrm{mGals}$ is deleted.

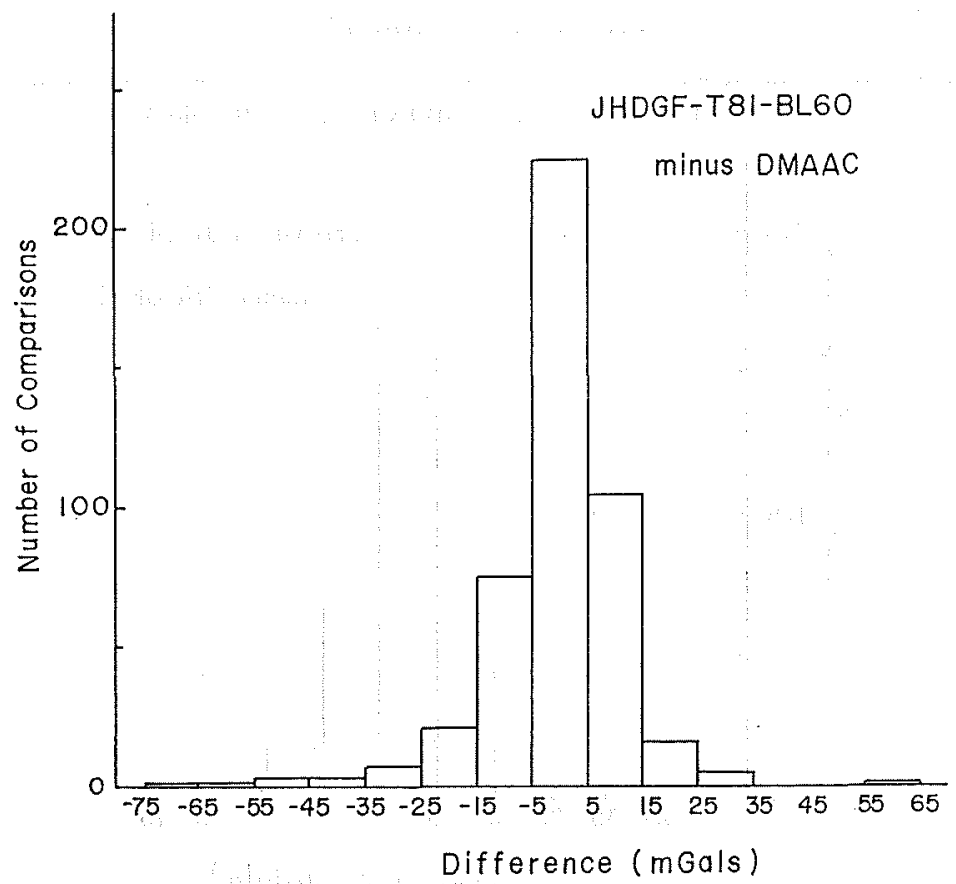

Figure $5 \mathrm{a}$ Comparison of $1^{\circ} \times 1^{\circ}$ block mean gravity anomalies between JHDGF-T81-BL60 and DMAAC data -463 blocks 


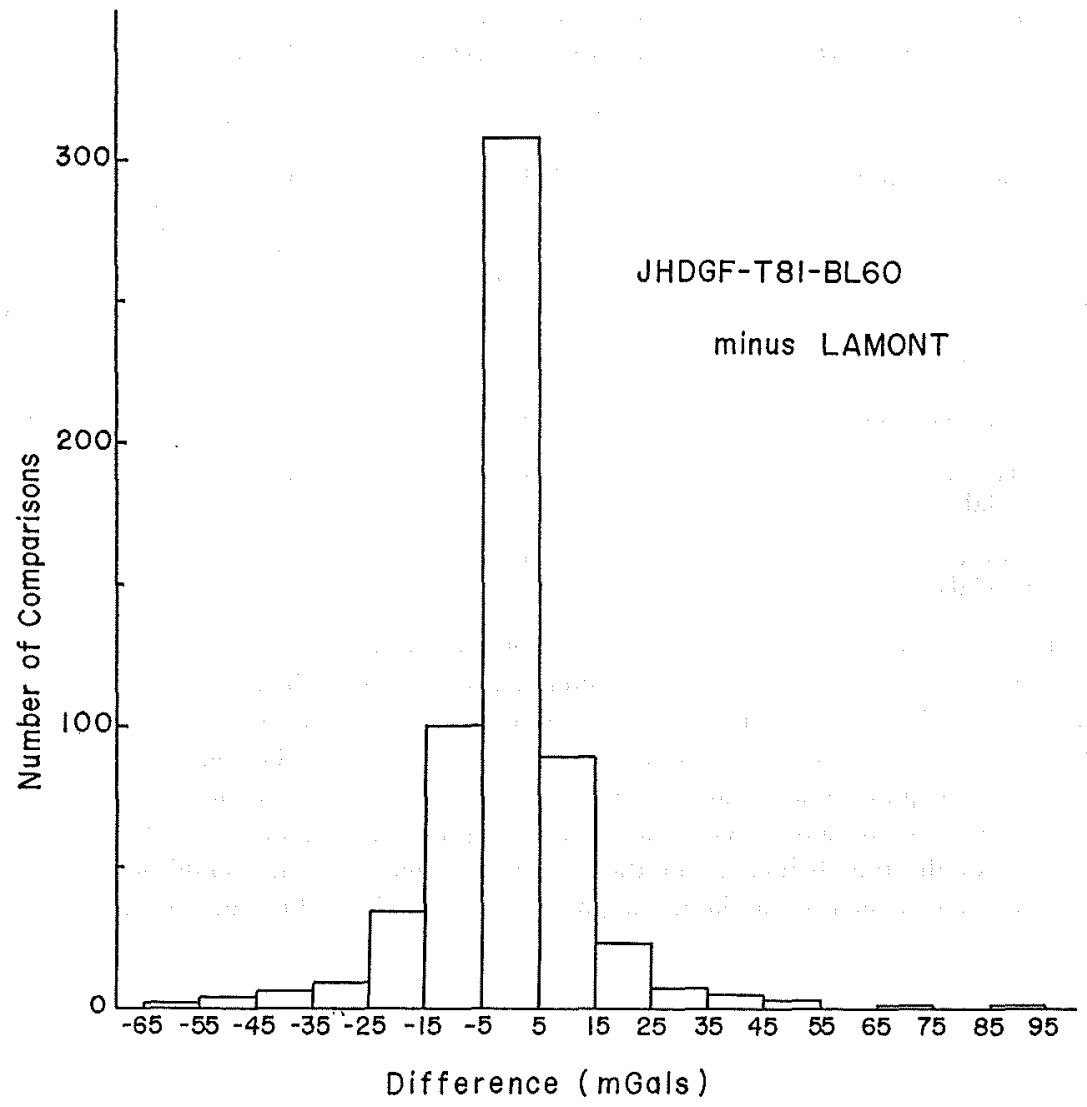

Figure $5 \mathrm{~b}$ Comparison of $1^{\circ} \times 1^{\circ}$ block mean gravity anomalies between JHDGF-T81-BL60 and LAMONT data -592 blocks

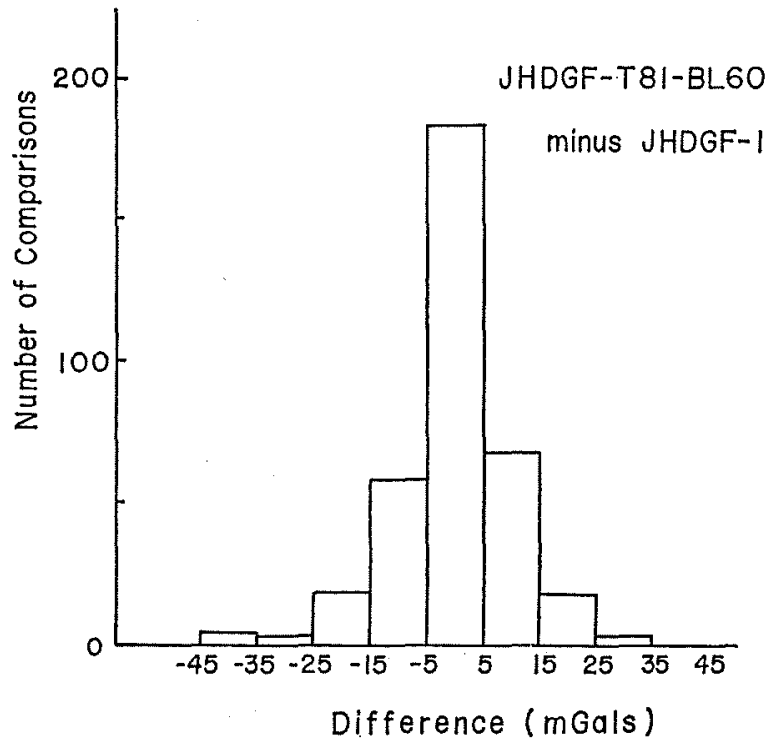

Figure $5 \mathrm{c}$ Comparison of $1^{\circ} \times 1^{\circ}$ block mean gravity anomalies between JHDGF-T81-BL60 and JHDGF-1 - 355 blocks 
the lime being. Calibration of the gravimetric geold should be made by other geodetic observations such as the laser rangings of LAGEOS satellite and the moon.

\section{Concluding remarks}

The feature of the gravity anomaly field in the vicinity of the continental shelf around Japan has been clarified by the gravity anomaly map presented with this paper. The map will be revised as soon as gravity data are newly added especially in the areas where gravity site are sparse as shown in Figure 1. JHD is preparing a large project of oceanic surveys in the Western Pacific. The gravity anomaly field in the region will be determined more in detail and accurately than shown in Figure 4. A new survey ship is under construction now, which is going to be equiped with highly advanced instruments for oceanic survey. An advanced sea gravity meter system will be of use for the accurate sea gravimetry and the cleaning up of the old data. The obtained block mean gravity anomalies compiled in a magnetic tape are used to compute a gravimetric geoid around Japan. The data file can also be used to produce a gravity anomaly contour map by use of a plotting machine. The geophysical interpretation of the gravity anomaly field is an interesting problem, and it is left as a later work.

\section{Acknowledgments}

The authors would like to thank K. Koyama and Y. Komatsu for their help in producing figures and maps, and T. Sato and H. Saito for their kind suggestion in publishing forms of the gravity anomaly maps.

\section{References}

Fujimoto, H. 1976 : "Processing of gravity data at sea and their geophysical interpretation in the region of the Western Pacific", Bull. Ocean Res. Inst., Univ. Tokyo No. 3, 1-81.

Ganeko, Y., Yanagi, T., Kubo, K. 1978 : "Gravity measurement at sea in 1973, 1974 and 1976", Data Report of Hydrographic Observations, Series of Astronomy and Geodesy, Japan Hydrographic Department, No. 12, 55-80.

Ganeko, Y. 1980 : "New determination of a marine geoid around Japan", Rep. Hydrographic Res., Japan Hydrographic Department, No. 15, 71-170.

Ganeko, Y., Koyama, K. 1981 : "Gravity data file of the Hydrographic Department and estimation of block mean gravity anomalies", Rep. Hydrographic Res., Japan Hydrographic Department, No. 16, 103-120.

Heiskanen, W., Moritz, H. 1967 : Physical Geodesy, W. H. Freeman, San Francisco, Calif., pp. 364,

Moritz, H. 1972 : "Advanced least-squares method", Rep. 175, Dep. Geod. Sci., Ohio State Univ. Res. Found., Ohio State Univ., pp. 133.

Segawa, J. 1970a : "Gravity measurement at sea by use of the T.S.S.G., Part 1", J. Phys. Earth, 18, $19-49$.

Segawa, J. 1970b : "Gravity measurement at sea by use of the T.S.S.G., Part 2", J. Phys. Earth, 18, 203-284.

Tomoda, Y., Kanamori, H. 1962 : "Tokyo Surface Ship Gravity Meter-1", J. Geod. Soc. Japan, 7, $116-145$.

Tomoda, Y., Fujimoto, H., Ganeko, Y. 1980 : "Interaction between trench and seamount in case of 
Kasima Seamount No. 1", Zisin, Journal of the Seismological Society of Japan, 33, 493-499.

Tomoda, Y., Fujimoto, H. 1980 : "Free air and Bouguer gravity anomaly in the West Pacific calculated from sea gravity data obtained by T.S.S.G.", J. Geod. Soc. Japan, 26, 258-266.

Wagner, C. A., Lerch, F. J., Bround, J. E., Richardson, J. A. 1976 : "Improvement in the geopotential derived from satellite and surface data (GEM 7 \& 8)", Rep. X-921-76-20, NASA/Goddard Space Flight Center, Greenbelt, Maryland, pp. 11.

Watts, A. B., Leeds, A. R. 1977 : "Gravimetric geoid in the Northwest Pacific Ocean", Geophys. J. R. astr. Soc., 50, 249-277. 